\title{
Correction: Beneficial bacteria inhibit cachexia
}

\section{Bernard J. Varian' ${ }^{1}$, Sravya Gourishetti ${ }^{1}$, Theofilos Poutahidis ${ }^{1,2}$, Jessica R. Lakritz ${ }^{1}$,} Tatiana Levkovich ${ }^{1}$, Caitlin Kwok ${ }^{1}$, Konstantinos Teliousis ${ }^{2}$, Yassin M. Ibrahim ${ }^{1}$, Sheyla Mirabal ${ }^{1}$ and Susan E. Erdman ${ }^{1}$

${ }^{1}$ Division of Comparative Medicine, Massachusetts Institute of Technology, Cambridge, MA, USA

${ }^{2}$ Laboratory of Pathology, Faculty of Veterinary Medicine, Aristotle University of Thessaloniki, Thessaloniki, Greece Published: June 29, 2018

Copyright: Varian et al. This is an open-access article distributed under the terms of the Creative Commons Attribution License 3.0 (CC BY 3.0), which permits unrestricted use, distribution, and reproduction in any medium, provided the original author and source are credited.

This article has been corrected: The corrected author name is given below:

\section{Sravya Gourishetti}

Original article: Oncotarget. 2016; 7:11803-11816. https://doi.org/10.18632/oncotarget.7730 